\title{
Mechanical Properties of Skins of Sweet Cherry Fruit of Differing Susceptibilities to Cracking
}

\author{
Martin Brüggenwirth and Moritz Knoche ${ }^{1}$ \\ Fruit Science Section, Institute for Biological Production Systems, Leibniz University Hannover, \\ Herrenhäuser Straße 2, 30419 Hannover, Germany
}

\begin{abstract}
Additional Index words. Prunus avium, epidermis, hypodermis, modulus of elasticity, strain, tensile test
Abstract. Rain cracking of sweet cherry fruit (Prunus avium L.) may be the result of excessive water uptake and/or of mechanically weak skins. The objectives were to compare mechanical properties of the skins of two cultivars of contrasting cracking susceptibility using biaxial tensile tests. We chose 'Regina' as the less-susceptible and 'Burlat' as the more-susceptible cultivar. Cracking assays confirmed that cracking was less rapid and occurred at higher water uptake in 'Regina' than in 'Burlat'. Biaxial tensile tests revealed that 'Regina' skin was stiffer as indexed by a higher modulus of elasticity $(E)$ and had a higher pressure at fracture $\left(p_{\text {fracture }}\right)$ than 'Burlat'. There was little difference in their fracture strains. Repeated loading, holding, and unloading cycles of the fruit skin resulted in corresponding changes in strains. Plotting total strains against the pressure applied for ascending, constant, and descending pressures yielded essentially linear relationships between strain and pressure. Again, 'Regina' skin was stiffer than 'Burlat' skin. Partitioning total strain into elastic strain and creep strain demonstrated that in both cultivars most strain was accounted for by the elastic component and the remaining small portion by creep strain. Differences in $E$ and $p_{\text {fracture }}$ between 'Regina' and 'Burlat' remained even after destroying their plasma membranes by a freeze/thaw cycle. This indicates that differences in skin mechanical properties must be accounted for by differences in the cell walls, not by properties related to cell turgor. Microscopy of skin cross-sections revealed no differences in cell size between 'Regina' and 'Burlat' skins. However, mass of cell walls per unit fresh weight was higher in 'Regina' than in 'Burlat'. Also, the ratio of tangential/radial diameters of epidermal cells was lower in 'Regina' $(1.86 \pm 0.12)$ than in 'Burlat' $(2.59 \pm 0.15)$. The results suggest that cell wall physical (and possibly also chemical) properties account for the cultivar differences in skin mechanical properties, and hence in cracking susceptibility.
\end{abstract}

Wherever sweet cherries are grown, rain-induced fruit cracking imposes a major limitation to production (Christensen, 1996). Susceptibility to rain cracking differs among cultivars (Christensen, 1995, 1999, 2000; Measham et al., 2009), but the mechanistic basis of differential cracking susceptibility among cultivars is not clear. From the coincidence of rainfall and fruit cracking, it is inferred that cracking is related to water uptake into the fruit. Water uptake, in turn, leads to an increase in volume, causing the fruit surface area to increase. When the limits of extensibility are exceeded, the fruit is expected to crack.

Based on the above logic, differential cracking susceptibility among cultivars could result from either (or both) of two, mechanistically unrelated, factors. First, the net import of water into the fruit will affect cracking by causing fruit volume to increase, thereby straining the skin beyond some defined upper limit. Second, mechanical properties of the fruit skin will affect the fracture limits. Recent investigations (Brüggenwirth et al., 2014) have established that it is the epidermal and hypodermal cell layers (not the cuticle) that represent the structural "backbone" of the skins of sweet cherry fruit. Thus, differences in cracking susceptibility among sweet cherry cultivars could be the result of different water-uptake characteristics and/or of

Received for publication 18 Nov. 2015. Accepted for publication 23 Dec. 2015. This research was funded in part by grants from the Deutsche Forschungsgemeinschaft.

We thank Dieter Reese and Christoph Knake for constructing, engineering, and programming the elastometer; Friederike Schroeder and Simon Sitzenstock for technical support; Bishnu P. Khanal and Sandy Lang for helpful discussion and useful comments on an earlier version of this manuscript.

${ }^{1}$ Corresponding author. E-mail: moritz.knoche@obst.uni-hannover.de. the mechanical properties of the epidermal and hypodermal cell layers.

Water uptake across the fruit surface has been studied in detail in the last decade. The pathways and mechanisms of transfer have been identified (Beyer et al., 2005; Knoche et al., 2000; Weichert and Knoche, 2006). However, among 29 cultivars, there was no close relationship between variation in cracking susceptibility and variation in the major characteristics of the fruit surface: water permeance, strain, mass of cuticle per unit area, stomatal density, etc. (Peschel and Knoche, 2012). Some information is available on vascular transport, but to our knowledge differences among cultivars have not been identified (Brüggenwirth and Knoche, 2015; Hovland and Sekse, 2004a, 2004b; Measham et al., 2009, 2010, 2014).

Little information is available on the mechanical properties of the sweet cherry fruit skin (Bargel et al., 2004). Recently, Brüggenwirth et al. (2014) modified the biaxial bulging test to quantify the mechanical properties of excised fruit skins under standardized laboratory conditions. Modifications included dimensional fixation of a skin segment in a washer before excision, to prevent any release of elastic strain [built up in the skin due to growth (Grimm et al., 2012)]. Silicone oil was used to give a hydrostatic pressure to the skin segment from the physiological inside to prevent uncontrolled water uptake from that side - this could have confounded the test results (Simon, 1977). In contrast to the more common, uniaxial tensile tests of engineering, biaxial tensile tests better mimic the growth stresses and strains occurring in vivo. In a spherical organ of nearly isotropic growth, stresses and strains are of course fairly uniformly biaxial, not uniaxial. Also, sweet cherry skin exhibits high Poisson ratio properties, so a uniaxial tensile test using 
a skin strip is associated with severe narrowing, and hence a gross overestimation of skin extensibility (Brüggenwirth et al., 2014).

The purpose of this study was to 1) quantify the key mechanical properties of two sweet cherry cultivars of contrasting cracking susceptibility, using a biaxial tensile test and 2) investigate the mechanistic basis of any differences between the two cultivars. Because many fruit may vary diurnally in diameter, and hence surface area (Lang, 1990; Measham et al., 2014; Montanaro et al., 2012; Ohta et al., 1997) and because this may cause the skin to fatigue, we also investigated the effects of repeated loading and unloading cycles on the mechanical properties of the fruit skin of the two cultivars.

\section{Materials and Methods}

Plant material. Fruit of sweet cherry 'Adriana', 'Burlat', 'Hedelfinger', 'Merchant', 'Regina', 'Sam', and 'Samba' grafted on 'Gisela5' (Prunus cerasus L. $\times$ Prunus canescens Bois) were collected from greenhouse-grown trees in the 2013 and 2014 seasons. All fruit were obtained from the experimental station of the Leibniz University, Hannover, Germany (lat. $52^{\circ} 14^{\prime} \mathrm{N}$, long. $9^{\circ} 49^{\prime} \mathrm{E}$ ). Water was supplied via drip irrigation. The drip irrigation was operated for 2 -h intervals (corresponding to $\approx 15 \mathrm{~mm}$ of precipitation) as needed based on visual inspection of the moisture of the top soil $(<20 \mathrm{~cm})$. Fruit were harvested at maturity and selected for uniformity (based on color and size) and were free of visual defects. All fruit for mechanical testing were processed within $12 \mathrm{~h}$ of harvest. When held for more than $2 \mathrm{~h}$, fruit was placed in a cold room at $5{ }^{\circ} \mathrm{C}$, for shorter periods of time fruit was held at ambient temperature and covered with a damp paper towel. The 'Regina' and 'Burlat' fruit used for microscopy of the crosssections of the fruit surface were fixed in Karnovsky solution (Karnovsky, 1965).

The Elastometer. For a detailed description of the elastometer, the reader is referred to Brüggenwirth et al. (2014). Briefly, an excised exocarp segment [ES (synonym fruit skin segment)] is mounted on a polymethylmethacrylate (Lucite ${ }^{\circledR}$; Mitsubishi Rayon Lucite Group, Southampton, UK) chamber filled with silicone oil (AK10; Wacker Chemie, Munich, Germany). The chamber is pressurized by driving a motorized piston into it, causing the volume of the chamber to decrease at a rate of $\approx 153 \mu \mathrm{L} \cdot \mathrm{min}^{-1}$. The volume displacement causes the chamber pressure to increase and the ES to bulge outward. The pressure inside the chamber and the extent of bulging are monitored using a pressure transducer (Typ 40PC100G; Honeywell, Morristown, NJ) and a displacement transducer (KAP-S/5N; AST Angewandte System Technik, Wolnzach, Germany) from a material testing machine (BXC-FR2.5TN; Zwick Roell, Ulm, Germany). To preserve the in vivo strain of the fruit skin following excision, a brass washer (aperture diameter $12 \mathrm{~mm}$ ) was glued to the shoulder of an intact sweet cherry fruit using cyanoacrylate adhesive (Loctite 406; Henkel/ Loctite Deutschland, Munich, Germany) (Knoche and Peschel, 2006). By cutting underneath the washer with a razor blade, an ES was excised having an average thickness of $\approx 2.4 \pm 0.02 \mathrm{~mm}$. The ES remained fixed to the washer after excision, which prevented relaxation, thereby maintaining the in vivo strain that existed before excision (Brüggenwirth et al., 2014; Knoche and Peschel, 2006). The ES so-obtained comprise cuticle, epidermis, hypodermis, and some adhering mesocarp tissue.

The surface area $(A)$ of the bulging ES is calculated from Eq. [1], where $r$ is the radius of the washer aperture and $h$ is the height of the bulge ES (Brüggenwirth et al., 2014).

$$
A=\left(r^{2}+h^{2}\right) \times \pi
$$

An estimate of the total strain $(\varepsilon)$ is obtained from the change in surface area $(\Delta A)$ relative to the initial surface area $\left(A_{0}\right)$ of the bulging ES and is given in Eq. [2].

$$
\varepsilon=\frac{\Delta A}{A_{0}}
$$

In some experiments, the modulus of elasticity $(E)$ was estimated from the height $(h)$ of the bulging ES, the radius $(r)$ of the aperture, the pressure $(p)$, and the thickness $(t)$ of the bearing layer $(t=0.1 \mathrm{~mm})$ using Eq. [3] (Brüggenwirth et al., 2014).

$$
E=\frac{p \times r^{2} \times\left(r^{2}+h^{2}\right)}{h^{3} \times t \times 2}
$$

All mechanical tests were performed at $22{ }^{\circ} \mathrm{C}$.

EXPERIMENTs. The modulus of elasticity [ $E$ (megapascals)], the pressure at fracture $\left[p_{\text {fracture }}\right.$ (kilopascals) $]$, and strain at fracture $\left[\varepsilon_{\text {fracture }}\right.$ (square millimeters per square millimeter)] was quantified for a range of cultivars. Biaxial tensile tests were carried out as described above.

Total, elastic, and creep strains and the effects of repeated loading, holding, and unloading cycles were measured for 'Regina' and 'Burlat'. These cultivars were selected because of their contrasting cracking susceptibilities (Christensen, 1999). ES were excised and mounted as described above. Experiments were initiated by increasing the pressure during the loading phase. During the subsequent holding phase, pressure was maintained constant and then decreased in the unloading phase. The time period for a complete loading/ holding/unloading cycle was $\approx 5$ minutes. Preliminary experiments established that the test protocol had to be adapted to the cultivar tested because fracture limits differed between 'Regina' and 'Burlat'. First, the pressure applied to 'Burlat' skin was about half of that in 'Regina'. Second, the number of loading and unloading cycles was reduced by half for 'Burlat' skin, compared with that for 'Regina'. Higher numbers of cycles resulted in fracture of the skins (M. Brüggenwirth, unpublished data). Three types of experiments were conducted. In the first experiment, the effect of increasing loading was studied by increasing the pressure stepwise in $5-\mathrm{kPa}$ increments ( 0 to $40 \mathrm{kPa}$ for 'Regina' and 0 to $20 \mathrm{kPa}$ for 'Burlat'). In the second experiment, pressure was held constant during each cycle (25 kPa for 'Regina' and $10 \mathrm{kPa}$ for 'Burlat'). The last experiment comprised pressures that decreased stepwise by $5-\mathrm{kPa}$ increments (40 to $0 \mathrm{kPa}$ for 'Regina' and 20 to $0 \mathrm{kPa}$ for 'Burlat'). Data were analyzed by partitioning the strain during each cycle into a total strain, an elastic strain, and a creep strain. The elastic strain was defined as the strain during the loading phase, and the creep strain was defined as the deformation occurring during the holding phase. Total strain represented the sum of the elastic strain and the creep strain.

The effect of eliminating cell turgor by destroying plasma membrane integrity was investigated in 'Regina' and 'Burlat'. 
To do this, the ES were frozen for 30 minutes at $-18{ }^{\circ} \mathrm{C}$, then thawed for 30 minutes at $22{ }^{\circ} \mathrm{C}$, and then tested in the elastometer.

Cracking and water uptake. Cracking and water uptake relationships were established for 'Regina' and 'Burlat' sweet cherry fruit by incubation in deionized water at $22{ }^{\circ} \mathrm{C}$. Water uptake was restricted to the fruit surface by previously sealing the stem cavity with silicone rubber (SE9186 Coating; Dow Corning, Midland, MI). Cracking was quantified in two batches of 25 fruit each, by visual inspection of fruit at $2,4,6,8,10$, and $24 \mathrm{~h}$ for macroscopically visible cracks. The time to $50 \%$ fruit cracking $\left(\mathrm{T}_{50}\right)$ was calculated using a four-parameter sigmoidal regression model, fitted to a plot of the percentage of fruit cracking vs. time (Winkler et al., 2015). Fruit that had cracked was removed from the solution, and noncracked fruit was returned for further incubation. Water uptake was quantified gravimetrically after 0.75 and $1.5 \mathrm{~h}(n=15)$. The water uptake required for $50 \%$ fruit cracking $\left(\mathrm{WU}_{50}\right)$ was calculated by multiplying the $\mathrm{T}_{50}$ by the rate of water uptake.

Microscopy. Dimensions of epidermal and hypodermal and parenchyma cells were quantified in fruit of 'Regina' and 'Burlat' fixed in Karnovsky solution (Karnovsky, 1965). Fruit were removed from the fixation solution and thoroughly washed in deionized water. Cross-sections were prepared from the shoulder region of the fruit, using parallel razor blades (spacing $3 \mathrm{~mm}$ ), and the sections were incubated for $7 \mathrm{~min}$ in $0.1 \%(\mathrm{w} / \mathrm{w})$ calcofluor white (fluorescent brightener 28; Sigma-Aldrich Chemie, Munich, Germany). Thereafter, cross-sections were rinsed with deionized water, positioned on a microscope slide, transferred to the stage of a fluorescence microscope (model BX-60; Olympus Europa, Hamburg, Germany), and viewed under ultraviolet light at $\times 400$ (model BX-60, filter U-MWB $330-385 \mathrm{~nm}$ excitation wavelength, $\geq 420 \mathrm{~nm}$ emission wavelength; Olympus Europa). Calibrated micrographs were taken using a digital camera (DP71, Olympus Europa), and the digital images were analyzed (software Cell`P, Olympus Europa). For the cells of the epidermis, hypodermis, and outer mesocarp, the cell sizes were measured (one radial and two tangential diameters) and the distances of the cell centers from the cuticle were quantified along a line drawn perpendicular to the fruit surface.

Mass of Cell walls. Tissue cylinders ( $8 \mathrm{~mm}$ diameter) were punched using a biopsy punch (Kai Europe, Solingen, Germany) and cut to discs of $2.5 \mathrm{~mm}$ height using parallel razor blades. The discs comprised cuticle, epidermis and hypodermis, and the outer mesocarp. Discs were frozen in liquid $\mathrm{N}_{2}$ and held at $-20{ }^{\circ} \mathrm{C}$. For analysis, discs were transferred into $3 \mathrm{~mL}$ of $80 \%$ ethanol, homogenized for 2 minutes, and thereafter heated to $80{ }^{\circ} \mathrm{C}$ for 15 minutes. Samples were then transferred into Eppendorf tubes and centrifuged at $20,800 g_{n}$. The supernatant was removed, the pellet washed with $2 \mathrm{~mL}$ of $80 \%$ ethanol, and centrifuged again. This procedure was repeated twice using pure acetone. Thereafter, the pellet was dried at $70{ }^{\circ} \mathrm{C}$ and weighed. Dry mass of cell walls per unit fresh weight was
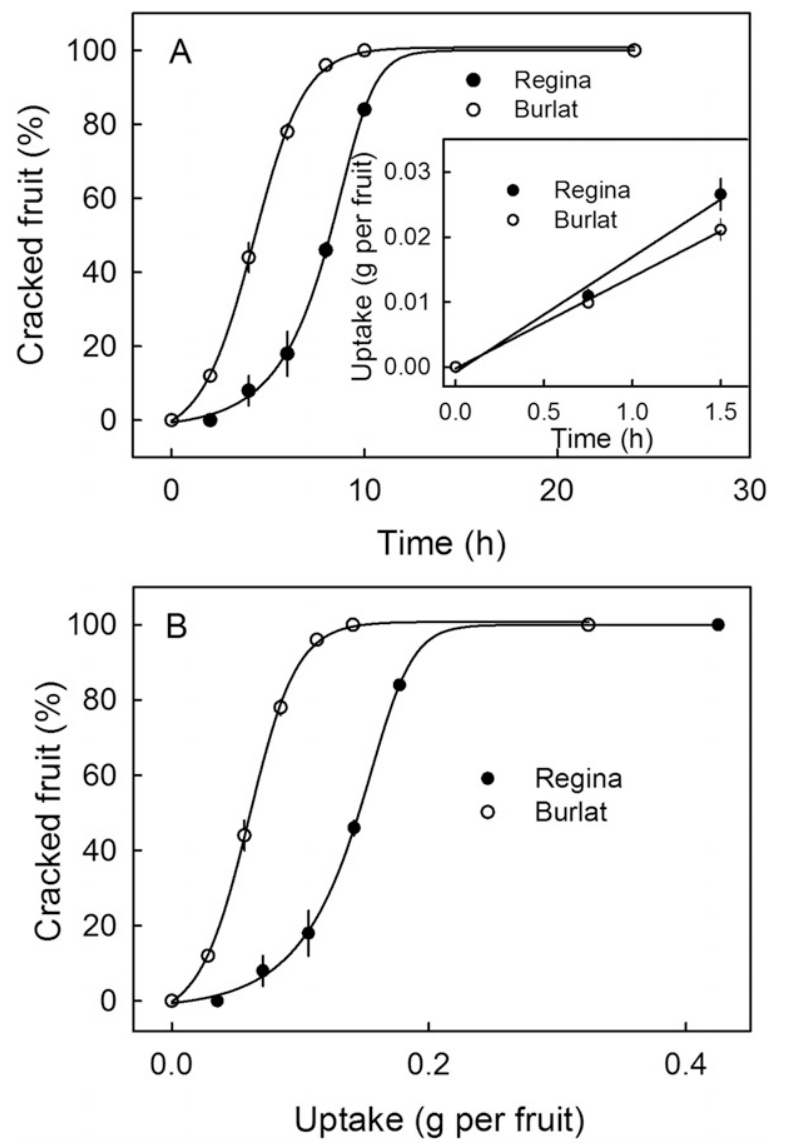

Fig. 1. (A) Time course of cracking and of water uptake (inset) of 'Regina' and 'Burlat' sweet cherry fruit incubated in deionized water. (B) Relationship between cracked fruit and water uptake. For further details, see Table 2.

calculated. The experiment was conducted with seven replicates comprising 10 discs per replicate.

Data Analysis. Data analysis was limited to segments that fractured in the center of the washer aperture. Segments fracturing at the edge of the aperture were excluded because artifacts resulting from the mounting procedure could not be excluded. Data are presented as means \pm SES of means. Mean comparisons were made using Tukey's studentized range test at $P<0.05$ (packet multcomp 1.2-12, procedure glht, R 2.13.1; R Foundation for Statistical Computing, Vienna, Austria). Significance of coefficients of correlation $(r)$ and of determination 
$\left(r^{2}\right)$ at the probability levels $0.05,0.01$, and 0.001 are indicated by $*, * *$, and $* * *$, respectively.

\section{Results}

The mechanical properties of the fruit skins differed significantly among cultivars (Table 1). 'Hedelfinger' and 'Regina' had the stiffest fruit skins as indexed by high values for $E$ and $p_{\text {fracture, }}$ whereas 'Burlat' had the lowest values for $E$ and $p_{\text {fracture. There }}$ was little difference among the various cultivars for the value of $\varepsilon_{\text {fracture, }}$ which ranged from 0.17 to 0.22 (Table 1).

Incubating fruit in deionized water resulted in cracking of both 'Regina' and 'Burlat' (Fig. 1). Cracking was markedly more rapid in 'Burlat' than in 'Regina' as indexed by a lower $\mathrm{T}_{50}$ (Table 2). Cumulative water uptake increased linearly with time (i.e., a constant uptake rate) in 'Regina' and 'Burlat' and occurred at similar rates in the two cultivars. Calculating cumulative water uptake at $50 \%$ cracking revealed that 'Regina' fruit required, on average, about three times more water to crack than 'Burlat' fruit (Table 2).

Repeated loading, holding, and unloading of the fruit skin imposed cyclic changes in the skin strains in both cultivars (Fig. 2). The maximum number of strain cycles sustained by 'Regina' segments was markedly higher than that by 'Burlat' segments (M. Brüggenwirth, unpublished data). Increasing pressure during any one loading cycle resulted in an instantaneous and proportional increase in strain. During the holding phase, the strain of the skins of both cultivars continued to increase. Upon release of the pressure, the skins of both cultivars returned to their initial dimensions, i.e., before the application of pressure.

Plotting total strains during any one cycle against the pressure applied for ascending, constant, or descending pressures yielded the relationships depicted in Fig. 3. In both cultivars, strains were essentially linearly related to the applied pressure with little difference between the ascending and descending paths [i.e., minimal hysteresis (Fig. 3)]. However, the slopes of the strain/pressure $\left(\mathrm{T}_{50}\right)$. relationships were markedly higher for the skins of 'Burlat' than for those of 'Regina' (Table 3). Thus, a given pressure caused markedly higher strain in the less stiff 'Burlat' skin than in the stiffer 'Regina' skin. Partitioning total strain into its elastic and creep components demonstrated that 1) most of the total strain in both cultivars was accounted for by the elastic component, with the creep strain being relatively small and 2) the slopes of both the elastic strain vs. pressure and of the creep strain vs. pressure relationships

Table 2. Water uptake and cracking in 'Burlat' and 'Regina' sweet cherry. Cracking was indexed by the amount of water uptake for $50 \%$ of fruit to crack $\left(\mathrm{WU}_{50}\right)$ or by time to $50 \%$ fruit cracking

\begin{tabular}{|c|c|c|c|}
\hline \multirow[b]{2}{*}{ Cultivar } & \multirow{2}{*}{$\frac{\text { Rate of water uptake }}{\left[\text { mean } \pm \text { SE }\left(\mathrm{mg} \cdot \mathrm{h}^{-1}\right)\right]}$} & \multicolumn{2}{|c|}{ Cracking } \\
\hline & & $\mathrm{WU}_{50}[$ mean $\pm \mathrm{sE}(\mathrm{mg})]$ & $\mathrm{T}_{50}[$ mean $\pm \mathrm{SE}(\mathrm{h})]$ \\
\hline Burlat & $14.1 \pm 1.1^{\mathrm{z}} \mathrm{a}$ & $50.5 \pm 2.3$ & $3.6 \pm 0.2$ \\
\hline Regina & $17.7 \pm 1.6 \mathrm{a}$ & $145.8 \pm 0.7$ & $8.2 \pm 0.4$ \\
\hline
\end{tabular}

${ }^{\mathrm{z}}$ Mean separation by $t$ test at $P<0.05$.

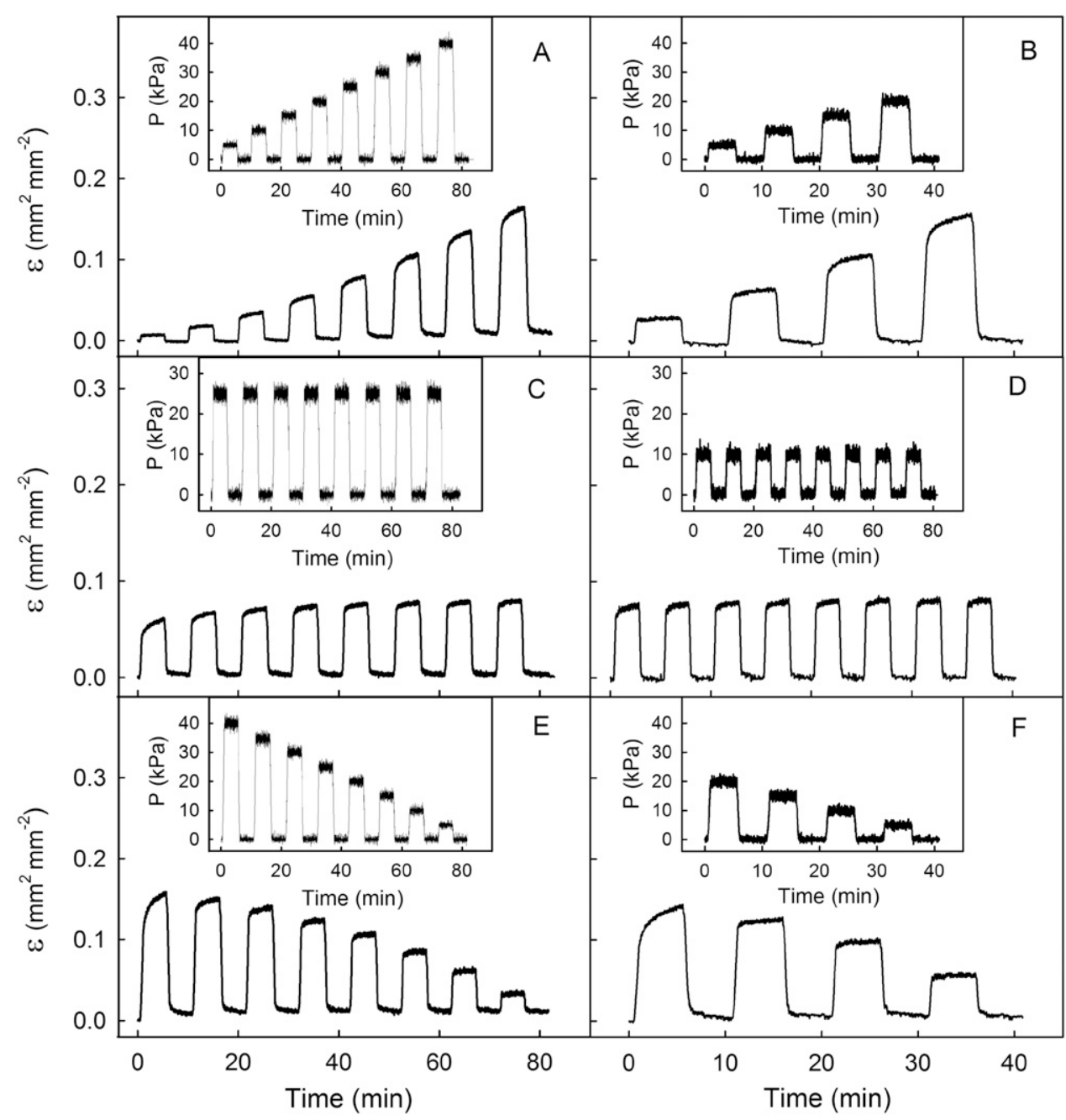

Fig. 2. Time course of change in strain of the fruit $\operatorname{skin}(\varepsilon)$ of $(\mathbf{A}, \mathbf{C}, \mathbf{E})$ 'Regina' and $(\mathbf{B}, \mathbf{D}, \mathbf{F})$ 'Burlat' sweet cherry when subjected to repeated loading, holding, and unloading cycles. (A, B) Pressures $(p)$ during the holding cycles were increased in $5-\mathrm{kPa}$ increments from 0 to $40 \mathrm{kPa}$ for 'Regina' and from 0 to $20 \mathrm{kPa}$ for 'Burlat'. (C, D) Pressures during the holding cycles were held constant at $25 \mathrm{kPa}$ for 'Regina' and $10 \mathrm{kPa}$ for 'Burlat'. (E, F) Pressures during the holding cycles were decreased stepwise in 5-kPa increments from 40 to $0 \mathrm{kPa}$ for 'Regina' and from 20 to $0 \mathrm{kPa}$ for 'Burlat'. Insets (A-F): Time courses of change in pressure. 
were markedly higher for 'Burlat' than for 'Regina' (Table 3).

Destroying the plasma membranes by a single freeze/thaw cycle decreased the values of both $E$ and $p_{\text {fracture. }}$. In 'Burlat', the value of $\varepsilon_{\text {fracture }}$ was increased by a single freeze/thaw cycle, but in 'Regina' there was no effect (Table 4). The $E$ and $p_{\text {fracture }}$ values of 'Regina' always exceeded those of 'Burlat'.

Cell sizes in both 'Regina' and 'Burlat' skins increased with increasing distance below the surface, to a depth of $\approx 200 \mu \mathrm{m}$ but remained constant thereafter (Fig. 4A and B). Cell sizes were similar in the two cultivars. Dry mass of cell walls per unit fresh weight, however, was higher in 'Regina' $(21.5 \pm 0.6$ $\mathrm{mg} \cdot \mathrm{g}^{-1}$ fresh weight) than in 'Burlat' $\left(15.8 \pm 0.6 \mathrm{mg} \cdot \mathrm{g}^{-1}\right.$ fresh weight). The shape of the cells as indexed by the anticlinal aspect ratio (i.e., tangential diameter/radial diameter) decreased with increasing distance from the surface. Cells at the surface had a lower aspect ratio in 'Regina' $\left(1.86 \pm 0.12, r^{2}=0.124^{* *}\right.$, $n=85$, estimated as the $y$-axis intercept of a linear regression line of a plot of aspect ratio vs. distance from the surface) than in 'Burlat' $\left(2.59 \pm 0.15, r^{2}=0.231^{* * *}, n=90\right)$. As distance

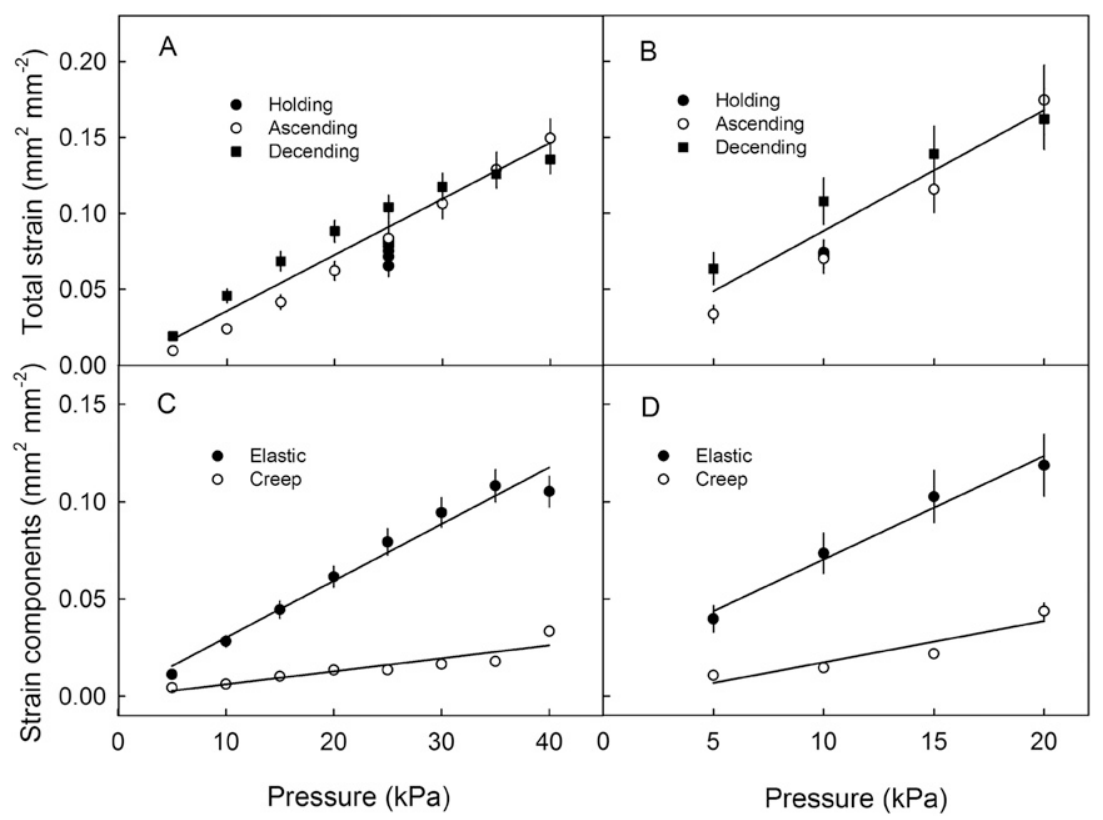

Fig. 3. (A, B) Total strains and (C, D) elastic and creep strains of the skin of $(\mathbf{A}, \mathbf{C})$ 'Regina' and $(\mathbf{B}, \mathbf{D})$ 'Burlat' sweet cherry as affected by the pressure applied in the elastometer. (A, B) Data from experiments with cyclic application of increasing, constant, or decreasing pressures. from the cuticle increased, cells became more closely isodiametric (aspect ratio $\approx 1$ ).

\section{Discussion}

Our data establish that 'Regina' and 'Burlat' differ in the mechanical properties in biaxial tensile tests of their fruit skins. The tensile tests show that 1 ) the skin of the less crackingsusceptible 'Regina' was stiffer and had a higher fracture pressure than that of the more cracking-susceptible 'Burlat', 2 ) the repeated loading and unloading cycles did not cause the skin to fatigue in either cultivar, and 3) the greater stiffness of 'Regina' is likely to result from differences in the physical and chemical properties of the cell walls of 'Regina' skin, compared with those of 'Burlat'.

'Regina' and 'Burlat' DIFFER IN MeChaniCal PROPERTIES OF THEIR FRUIT SKINS. The higher cracking susceptibility of 'Burlat' than of 'Regina' is consistent with published ratings (Christensen, 1999) and correlates with a weaker mechanical architecture of the fruit's skin. First, the rates of water uptake did not differ, but cracking was faster (lower $\mathrm{T}_{50}$ ) in 'Burlat' than in 'Regina'. This resulted in a lower $\mathrm{WU}_{50}$ in 'Burlat'. Thus, cracking in 'Burlat' required only one-third the amount of water uptake as in 'Regina'. Second, direct evidence for a weaker skin of 'Burlat' than 'Regina' comes from the biaxial tensile tests. The cultivar comparison established a lower value of $E$, and hence a low resistance to extension for 'Burlat' than for 'Regina' (Table 1). Also, the value $p_{\text {fracture }}$ for 'Burlat' was less than half than that for 'Regina' (Table 1). These two cultivars fell one at the upper end and the other at the lower end of the range of mechanical properties of the seven cultivars investigated here. The number of loading/holding/unloading cycles that could be applied without fracture in 'Regina' was twice that in 'Burlat' (M. Brüggenwirth, unpublished data). Finally, the slopes of the relationships between total strain and the elastic and the creep strain components vs. pressure were larger in 'Burlat' than in 'Regina'. This indicates that a given strain was reached at a lower pressure in 'Burlat' than in 'Regina' (Fig. 3). While the relationship between the lower stiffness

Table 3. Parameter estimates and sEs of linear regression equations describing the relationships between the pressure (kilopascals) applied in the elastometer and total strain, elastic strain, and creep strain (all strains millimeter square per millimeter square) of 'Regina' and 'Burlat' sweet cherry fruit skin.

\begin{tabular}{lcccc}
\hline & & \multicolumn{2}{c}{ Parameter estimates } & \multicolumn{2}{c}{ Coefficient of determination } \\
\cline { 2 - 3 } Cultivar & Strain component & $4.2 \pm 0.2$ & $\left[\times 10^{3}\right.$ (intercept $\left.\left.\pm \mathrm{SE}\right)\right]$ & $r^{2}$ \\
Regina & Total & $2.9 \pm 0.2$ & $-1.5 \pm 5.2$ & $0.99^{* * *}$ \\
& Elastic & $0.9 \pm 1.1$ & $0.98^{*}$ \\
Creep & $0.7 \pm 0.1$ & $-0.6 \pm 2.9$ & 0.91 \\
& Total & $7.7 \pm 0.7$ & $9.1 \pm 9.3$ & $0.99 * * *$ \\
& Elastic & $5.3 \pm 0.6$ & $17.1 \pm 7.8$ & $0.98^{* *}$ \\
& Creep & $2.1 \pm 0.6$ & $-3.9 \pm 8.1$ & 0.93 \\
\hline
\end{tabular}

${ }^{\mathrm{z}}$ Significance of coefficient of determination at $P<0.05,0.01$, and 0.001 indicated by $*, * *$, and $* * *$, respectively. 
Table 4. Effect of destroying plasma membranes of exocarp segments excised from the cheeks of mature 'Burlat' and 'Regina' sweet cherry fruit by a freeze/thaw cycle. The effects on the modulus of elasticity $(E)$, pressure at fracture $\left(p_{\text {fracture }}\right)$, and strain at fracture $\left(\varepsilon_{\text {fracture }}\right)$ were investigated $(n=20)$

\begin{tabular}{|c|c|c|c|c|}
\hline Cultivar & Treatment & $\frac{E}{[\text { mean } \pm \mathrm{SE}(\mathrm{MPa})]}$ & $\frac{p_{\text {fracture }}}{[\text { mean } \pm \mathrm{SE}(\mathrm{kPa})]}$ & $\frac{\varepsilon_{\text {fracture }}}{\left[\mathrm{mean} \pm \mathrm{SE}\left(\mathrm{mm}^{2} \cdot \mathrm{mm}^{-2}\right)\right]}$ \\
\hline \multirow[t]{2}{*}{ Burlat } & Control & $15.5 \pm 2.0^{\mathrm{z}} \mathrm{c}$ & $26.7 \pm 1.6^{\mathrm{z}} \mathrm{c}$ & $0.16 \pm 0.01^{\mathrm{z}} \mathrm{b}$ \\
\hline & Freeze/thaw & $5.3 \pm 0.4 \mathrm{~d}$ & $12.5 \pm 0.8 \mathrm{~d}$ & $0.20 \pm 0.01 \mathrm{a}$ \\
\hline \multirow[t]{2}{*}{ Regina } & Control & $33.9 \pm 1.9 \mathrm{a}$ & $64.5 \pm 2.2 \mathrm{a}$ & $0.17 \pm 0.01 \mathrm{~b}$ \\
\hline & Freeze/thaw & $25.7 \pm 2.3 b$ & $45.5 \pm 2.5 b$ & $0.16 \pm 0.01 \mathrm{~b}$ \\
\hline
\end{tabular}

${ }^{\mathrm{z}}$ Mean separation by Tukey's studentized range test at $P<0.05$.

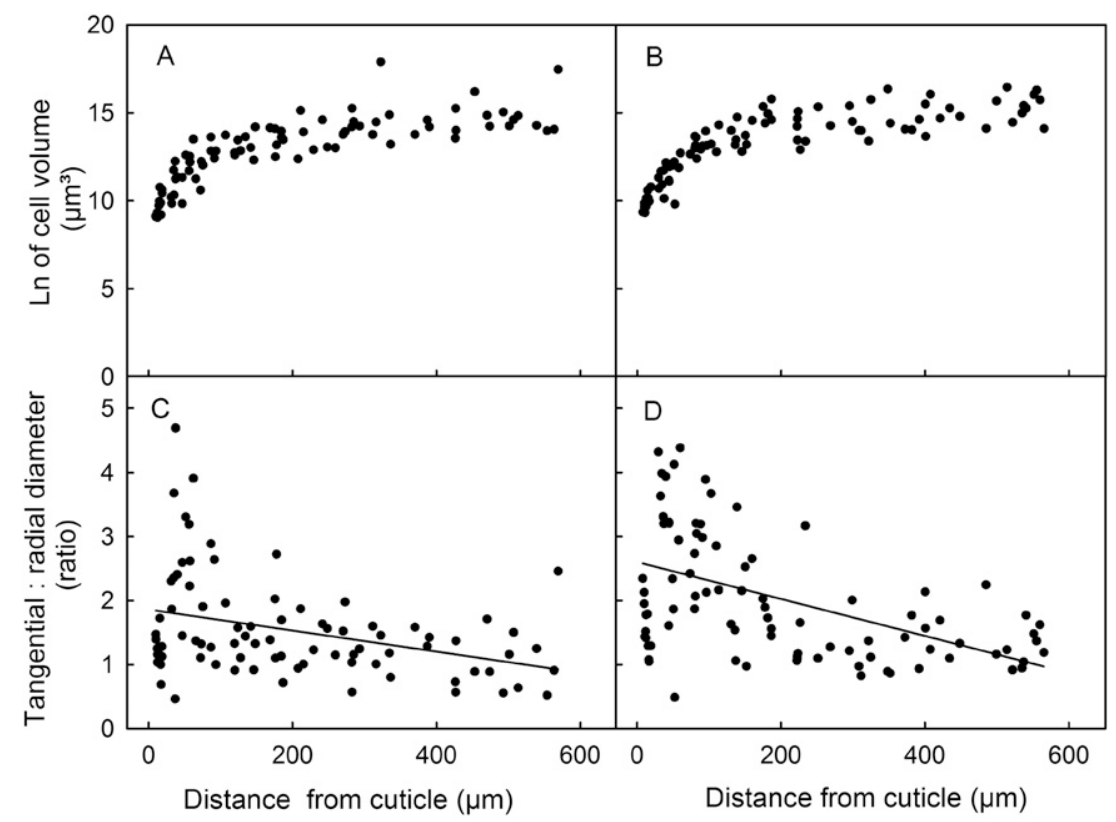

Fig. 4. Properties of cells of cross-sections through the skin of $(\mathbf{A}, \mathbf{C})$ 'Regina' and (B, D) 'Burlat' sweet cherry fruit. (A, B) Relationship between the logarithm of cell volume and the distance of cell centers from the cuticle. (C, D) Relationship between the ratio of tangential to radial diameters of cells and the distance of cell centers from cuticle.

and lower fracture pressure of the cracking-susceptible 'Burlat' vs. the higher values of these of the less cracking-susceptible 'Regina' are merely correlative (i.e., they are not necessarily causal), nevertheless they are consistent with the general concept in material science that for a pressurized hollow vessel, a weaker shell increases the likelihood of failure.

MEChANICAL BEHAVIOR OF FRUIT SKIN IN LOADING/UNLOADING CYCLES. Increasing the number of loading/unloading cycles did not change skin stiffness or fracture threshold (Fig. 3). Also, it made little difference whether the loads increased, decreased, or were maintained constant. Unlike tomato (Solanum lycopersicum L.) skin (Matas et al., 2004), there was no strain hardening in sweet cherry. In both cherry cultivars, elastic strain accounted for most of the deformation, whereas creep strain during the holding phases was low. These findings suggest diurnal oscillations in the diameter of a developing fruit (Measham et al., 2014) are unlikely to weaken the fruit skin.

Greater STIFFNESS OF 'ReginA' SKIN IS THE RESULT OF DIFFERENT PHYSICAL AND CHEMICAL PROPERTIES OF THE CELL wALLS. The tissue's water relation affects its mechanical properties. For example, the shape of a turgid cell resists change as a result of the tangential tension in the cell wall. However, when we destroyed the plasma membrane by imposing a freeze:thaw cycle, the value of $E$ remained five times higher and that of $p_{\text {fracture }}$ three times higher in 'Regina' than in 'Burlat'. Hence, because the difference persists in spite of turgor loss, the different $E$ and $p_{\text {fracture }}$ values of these two cultivars must be related to differences in the cell walls themselvesnot to cell turgor differences. The reason for the different cell wall mechanical properties of 'Burlat' and 'Regina' is unknown, but a number of factors may be involved:

First, mass of cell walls per unit fruit mass was higher in 'Regina' than in 'Burlat'. Also, microscopy indicates that the epidermis of 'Regina' has thicker anticlinal cell walls $(2.6 \pm 0.1 \mu \mathrm{m})$ than 'Burlat' $(2.2 \pm 0.1 \mu \mathrm{m})$ (C. Schumann, unpublished data). Cell wall thickness will affect the mechanical properties. Second, the epidermal cells of 'Burlat' had a higher mean anticlinal aspect ratio than those of 'Regina'. This is consistent with greater strain during growth and/or with less strain relaxation upon preparation of skin sections for microscopy. Third, cell walls could differ in their compositions - differences in cell wall composition can result in differential mechanical behaviors (Chanliaud et al., 2002). For example, the mechanical properties, such as firmness, of a range of sweet cherry cultivars were related to the chemistry of their cell walls, in particular to the composition and solubility of pectin (Basanta et al., 2013; Batisse et al., 1996; Salato et al., 2013). At this stage we do not know which of these factors is the most critical. Based on earlier data from our laboratory a role of the cuticle in mechanical properties of the sweet cherry fruit skin can be excluded (Brüggenwirth et al., 2014).

\section{Conclusions}

Biaxial tensile tests establish that the less cracking-susceptible fruit skin of 'Regina' was stiffer and fractured at a higher pressure than the more cracking-susceptible 'Burlat'. These differences in mechanical properties probably result from different physical and/or chemical properties of the cell walls. Further studies are required to establish relationships between the physical and chemical properties of the cell walls and their mechanical characteristics.

As in earlier studies, the pressures at fracture were of a similar order of magnitude to those reported previously for both cell and fruit turgor (Brüggenwirth and Knoche, 2016; Knoche et al., 2014; Schumann et al., 2014). However, the strains at fracture, resulting from surface area increase following water uptake $(0.3 \%$ to $1.1 \%)$, were markedly lower in the 
cracking assay than in the biaxial tensile tests. The reason for this striking discrepancy is unknown and deserves further study. A possible explanation is that cracking at the wholefruit level is a "local" phenomenon, where failure is triggered by a weak point somewhere in the skin of the whole fruit, whereas the much smaller area of skin employed in the biaxial tensile test will reduce the chances of including such a weak spot in the sample, so its result is proportionately more likely to be representative of a "perfect" fruit skin (Brüggenwirth and Knoche, 2016).

\section{Literature Cited}

Bargel, H., H.C. Spatz, T. Speck, and C. Neinhuis. 2004. Twodimensional tension tests in plant biomechanics: Sweet cherry fruit skin as a model system. Plant Biol. 6:432-439.

Basanta, F.M., M.F. de Escalada Plaì, C.A. Stortz, and A.M. Rojas. 2013. Chemical and functional properties of cell wall polymers from two cherry varieties at two developmental stages. Carbohydr. Polym. 92:830-841.

Batisse, C., M. Buret, and P.J. Coulomb. 1996. Biochemical differences in cell wall of cherry fruit between soft and crisp fruit. J. Agr. Food Chem. 44:453-457.

Beyer, M., S. Lau, and M. Knoche. 2005. Studies on water transport through the sweet cherry fruit surface: IX. Comparing permeability in water uptake and transpiration. Planta 220:474-485.

Brüggenwirth, M., H. Fricke, and M. Knoche. 2014. Biaxial tensile tests identify epidermis and hypodermis as the main structural elements of sweet cherry skin. Ann. Bot. Plants 6:plu019.

Brüggenwirth, M. and M. Knoche. 2015. Xylem conductance of sweet cherry pedicels. Trees (Berl.) 29:1851-1860.

Brüggenwirth, M. and M. Knoche. 2016. Factors affecting mechanical properties of the skin of sweet cherry fruit. J. Amer. Soc. Hort. Sci. 141:45-53.

Chanliaud, E., K.M. Burrows, G. Jeronomidis, and M.J. Gidley. 2002. Mechanical properties of primary plant cell wall analogues. Planta 215:989-996.

Christensen, J.V. 1995. Evaluation of fruit characteristics of 20 sweet cherry cultivars. Fruit Var. J. 49:113-117.

Christensen, J.V. 1996. Rain-induced cracking of sweet cherries. Its causes and prevention, p. 297-327. In: A.D. Webster and N.E. Looney (eds.). Cherries. CAB Intl., Wallingford, UK.

Christensen, J.V. 1999. An evaluation of sweet cherry cultivars. Danish Institute of Agricultural Sciences, Årslev, Denmark.

Christensen, J.V. 2000. Performance in Denmark of 16 European varieties of sweet cherry. J. Amer. Pomol. Soc. 54:172-176.

Grimm, E., S. Peschel, T. Becker, and M. Knoche. 2012. Stress and strain in the sweet cherry fruit skin. J. Amer. Soc. Hort. Sci. 137:383390.

Hovland, K.L. and L. Sekse. 2004a. Water uptake through sweet cherry (Prunus avium L.) fruit pedicels: Influence of fruit surface water status and intact fruit skin. Acta Agr. Scand. Sect. B Soil Plant Sci. 54:91-96.
Hovland, K.L. and L. Sekse. 2004b. Water uptake through sweet cherry (Prunus avium L.) fruit pedicels in relation to fruit development. Acta Agr. Scand. Sect. B Soil Plant Sci. 54:264-266.

Karnovsky, M.J. 1965. A formaldehyde-glutaraldehyde fixative of high osmolality for use in electron microscopy. J. Cell Biol. 27:137A-138A.

Knoche, M. and S. Peschel. 2006. Water on the surface aggravates microscopic cracking of the sweet cherry fruit cuticle. J. Amer. Soc. Hort. Sci. 131:192-200.

Knoche, M., S. Peschel, M. Hinz, and M. Bukovac. 2000. Studies on water transport through the sweet cherry fruit surface: Characterizing conductance of the cuticular membrane using pericarp segments. Planta 212:127-135.

Knoche, M., E. Grimm, and H.J. Schlegel. 2014. Mature sweet cherries have low turgor. J. Amer. Soc. Hort. Sci. 139:3-12.

Lang, A. 1990. Xylem, phloem and transpiration flows in developing apple fruits. J. Expt. Bot. 41:645-651.

Matas, A.J., E.D. Cobb, J.A. Bartsch, D.J. Paolillo, and K.J. Niklas. 2004. Biommechanics and anatomy of Lycopersicum esculentum fruit peels and enzyme-treated samples. Amer. J. Bot. 91:352-360.

Measham, P.F., S.A. Bound, A.J. Gracie, and S.J. Wilson. 2009. Incidence and type of cracking in sweet cherry (Prunus avium L.) are affected by genotype and season. Crop Pasture Sci. 60:1002-1008.

Measham, P.F., S.A. Bound, A.J. Gracie, and S.J. Wilson. 2010. Vascular flow of water induces side cracking in sweet cherry (Prunus avium L.). Adv. Hort. Sci. 24:243-248.

Measham, P.F., S.J. Wilson, A.J. Gracie, and S.A. Bound. 2014. Tree water relations: Flow and fruit. Agr. Water Mgt. 137:59-67.

Montanaro, G., B. Dichio, C. Xiloyannis, and A. Lang. 2012. Fruit transpiration in kiwifruit: Environmental drivers and predictive model. Ann. Bot. Plants 6:pls036.

Ohta, K., T. Hosoki, K. Matsumoto, M. Ohya, N. Ito, and K. Inaba. 1997. Relationships between fruit cracking and changes of fruit diameter associated with solute flow to fruit in cherry tomatoes. J. Jpn. Soc. Hort. Sci. 65:753-759.

Peschel, S. and M. Knoche. 2012. Studies on water transport through the sweet cherry fruit surface: XII. Variation in cuticle properties among cultivars. J. Amer. Soc. Hort. Sci. 137:367-375.

Salato, G.S., N.M.A. Ponce, M.D. Raffo, A.R. Vicente, and C.A. Stortz. 2013. Developmental changes in cell wall polysaccharide from sweet cherry (Prunus avium L.) cultivars with contrasting firmness. Postharvest Biol. Technol. 84:66-73.

Schumann, C., H.J. Schlegel, E. Grimm, M. Knoche, and A. Lang. 2014. Water potential and its components in developing sweet cherry. J. Amer. Soc. Hort. Sci. 139:349-355.

Simon, E.W. 1977. Leakage from fruit cells in water. J. Expt. Bot. 28:1147-1152.

Weichert, H. and M. Knoche. 2006. Studies on water transport through the sweet cherry fruit surface: 10 . Evidence for polar pathways across the exocarp. J. Agr. Food Chem. 54:3951-3958.

Winkler, A., M. Ossenbrink, and M. Knoche. 2015. Malic acid promotes cracking of sweet cherry fruit. J. Amer. Soc. Hort. Sci. 140:280-287. 